\title{
ON THE QUESTION OF WHETHER DIGITAL RIGHTS SHOULD BE INTRODUCED INTO THE CIVIL CODE
}

\author{
Alexey Yu. Churilov \\ Tomsk State University, Tomsk, Russian Federation
}

Introduction: on October 1, 2019, Article 141.1 "Digital rights" was introduced into the Civil Code by Federal law No. 34-FZ of 18.03.2019. Since January 1, 2020, the so-called utilitarian digital rights have been introduced into civil circulation. In connection with such significant changes in the objects of civil rights, there appears a need for a thorough analysis of innovations in terms of their feasibility and necessity. The tasks set by the author correspond to the goal of analyzing the legal regime of digital rights: to conduct a comparative analysis of securities, primarily non-documentary ones, and digital rights. Methods: the methodological framework for the research is a set of methods of scientific knowledge, among which the main ones are the methods of historicism, systematicity, analysis, and comparison. Results: the paper examines the category "digital rights" introduced in the Civil Code of the Russian Federation, as well as the special legislation regulating the utilitarian digital rights. The comparison of nondocumentary securities and utilitarian digital rights is made. The author studied the property rights that might be the content of digital rights, as well as the specifics of fixing digital rights in comparison with non-documentary securities, and the specifics of transferring digital rights from one person to another. A new non-documentary nonemissive security that mediates the circulation of digital rights - the digital certificate - is studied. Conclusions: the paper substantiates the inexpediency of introducing such an object of civil rights as digital rights into the Civil Code of the Russian Federation. The conclusion is made about the excessive complexity of the structure of digital rights and digital certificates, as well as the difficulties of using them for the investment purposes.

Key words: civil rights objects, digital law, security, utilitarian digital law, non-documentary security.

Citation. Churilov A.Yu. On the Question of Whether Digital Rights Should Be Introduced into the Civil Code. Legal Concept, 2020, vol. 19, no. 2, pp. 105-109. (in Russian). DOI: https://doi.org/10.15688/lc.jvolsu.2020.2.15

\section{К ВОПРОСУ О ЦЕЛЕСООБРАЗНОСТИ ВВЕДЕНИЯ В ГРАЖДАНСКИЙ КОДЕКС ЦИФРОВЫХ ПРАВ}

\author{
Алексей Юрьевич Чурилов \\ Томский государственный университет, г. Томск, Российская Федерация
}

Введение: с 1 октября 2019 г. в Гражданский кодекс Федеральным законом от 18.03.2019 № 34-Ф3 была введена ст. 141.1 «Цифровые права». С 1 января 2020 г. в гражданский оборот были введены так называемые утилитарные цифровые права. В связи с такими существенными изменениями объектов гражданских прав возникла необходимость тщательного анализа нововведений с точки зрения их целесообразности и необходимости. Выполнению цели анализа правового режима цифровых прав соответствуют поставленные автором задачи: провести сравнительный анализ ценных бумаг, в первую очередь бездокументарных, и цифроав. Методы: методологическую основу исследования составляет совокупность методов научного познания, среди которых основное место занимают методы историзма, системности, анализа, а также сраво нения. Результаты: исследована введенная в ГК РФ категория «цифровые права», а также специальное законодательство, регулирующее утилитарные цифровые права. Проведено сравнение бездокументарных ценных бумаг и утилитарных цифровых прав. Были изучены те имущественные права, которые могут являть() ся содержанием цифровых прав, а также особенность фиксации цифровых прав по сравнению с бездоку- 
ментарными ценными бумагами, особенности перехода цифровых прав от одного лица другому. Исследована новая бездокументарная неэмиссионная ценная бумага, опосредующая оборот цифровых прав - цифровое свидетельство. Выводы: обоснована нецелесообразность введения в ГК РФ такого объекта гражданских прав, как цифровые права. Сделан вывод о чрезмерном усложнении конструкции цифровых прав и цифровых свидетельств, а также о трудностях их использования в целях инвестирования.

Ключевые слова: объекты гражданских прав, цифровое право, ценная бумага, утилитарное цифровое право, бездокументарная ценная бумага.

Цитирование. Чурилов А. Ю. К вопросу о целесообразности введения в гражданский кодекс цифровых прав // Legal Concept = Правовая парадигма. -2020 . - T. 19, № 2. - C. 105-109. - DOI: https://doi.org/10.15688/ lc.jvolsu.2020.2.15

\section{Введение}

1 октября 2019 г. вступил в силу Федеральный закон от 18.03.2019 № 34-Ф3 «О внесении изменений в части первую, вторую и статью 1124 части третьей Гражданского кодекса Российской Федерации», внесший изменения в ст. 128 Гражданского кодекса Российской Федерации (далее - ГК РФ), а также включивший в ГК РФ ст. 141.1 «Цифровые права», а с 1 января 2020 г. вступил в силу Федеральный закон от 02.08.2019 № 259-Ф3 «О привлечении инвестиций с использованием инвестиционных платформ и о внесении изменений в отдельные законодательные акты Российской Федерации» (далее - Закон об инвестиционных платформах), первый (и в настоящее время единственный) закон, закрепивший правовой режим цифровых прав.

\section{Понятие цифровых прав}

В соответствии со ст. 141.1 ГК РФ цифровыми правами признаются названные в таком качестве в законе обязательственные и иные права, содержание и условия осуществления которых определяются в соответствии с правилами информационной системы, отвечающей установленным законом признакам. Примечательно, что это определение во многом совпадает с определением ценной бумаги, закрепленной в ГК РФ. Поскольку цифровое право, в силу своей нематериальной природы и существования строго в электронном виде, с документарной ценной бумагой соотноситься не может a priori, приведем определение бездокументарной ценной бумаги: ценными бумагами признаются обязательственные и иные права, которые закреплены в решении о выпуске или ином акте лица, вы- пустившего ценные бумаги в соответствии с требованиями закона, и осуществление и передача которых возможны только с соблюдением правил учета этих прав.

В этой связи необходимо выделить признаки цифровых прав, общие с бездокументарными ценными бумагами, а также те, которые отличаются от них.

\section{Содержание цифровых прав}

Очевидно, что содержание цифровых прав и ценных бумаг (как документарных, так и бездокументарных) одинаковое: его составляют обязательственные и иные, в том числе корпоративные, права. Различной является лишь форма закрепления этих имущественных прав как в самом объекте права, так и форма закрепления этих объектов за правообладателем, а также порядок реализации этих прав.

Применительно к цифровым правам, единственным действующим законом в этой сфере закреплены следующие имущественные права (ст. 8 Закона об инвестиционных платформах), которые могут являться содержанием цифрового права:

1) право требовать передачи вещи (вещей);

2) право требовать передачи исключительных прав на результаты интеллектуальной деятельности и (или) прав использования результатов интеллектуальной деятельности;

3) право требовать выполнения работ и (или) оказания услуг.

Небезынтересно, что Закон об инвестиционных платформах относит такие цифровые права к «утилитарным», что позволяет предположить существование неких «неутилитарных» цифровых прав, о которых действующее законодательство умалчивает. Некоторые авторы называют утилитарные цифровые пра- 
ва отечественным аналогом «токенов» [6], с чем можно согласиться, поскольку токен представляет собой единицу учета определенной экономической ценности [2], зафиксированной в системе блокчейн, но с той оговоркой, что «токен» по содержанию является более широким понятием, нежели предусмотренное отечественным законодательством цифровое право, поскольку могут существовать и так называемые корпоративные токены, закрепляющие корпоративные права [4].

Законодатель таким образом существенно расширяет содержание цифровых прав по сравнению с бездокументарными и документарными ценными бумагами. И если право требовать передачи вещей, в частности, груза, еще можно встретить в содержании ценных бумаг (например, коносамента), то остальные два права - нет. Однако существуют и ограничения, касающиеся содержания утилитарных цифровых прав. Так, содержанием утилитарного цифрового права не может являться право требовать имущество, права на которое подлежат государственной регистрации, и (или) право требовать имущество, сделки с которым подлежат государственной регистрации или нотариальному удостоверению. Связано это с особыми требованиями к документам, предоставляемым для регистрации перехода прав на недвижимое имущество [3], а также с тем, что в настоящее время утилитарное цифровое право не может приравниваться к нотариальной форме сделки.

Вместе с тем вопрос о целесообразности введения нового объекта, новой категории, в гражданский оборот ради того, что можно было бы сделать расширением содержания бездокументарных ценных бумаг, либо с сохранением действующих договорных конструкций в сфере инвестирования, остается открытым.

\section{Фиксация цифровых прав}

Презентативность как признак документарных ценных бумаг не присущ объектам, не существующим в материальной форме, в том числе и цифровым правам. По общему правилу утилитарное цифровое право возникает у первого приобретателя с момента внесения информации об этом в инвестиционной плат- форме в соответствии с правилами этой инвестиционной платформы [5]. В этом порядок возникновения и фиксации цифровых прав схож с порядком возникновения и фиксации бездокументарных ценных бумаг, которые возникают с момента принятия решения о выпуске (в случаях, предусмотренных законом, требуется регистрация выпуска). Следует отметить, что в литературе идет дискуссия относительно момента возникновения бездокументарной ценной бумаги. Выделяются три основные точки зрения на этот вопрос: первая основывается на том, что ценные бумаги как объект возникли с момента государственной регистрации выпуска; вторая - на этапе размещения ценных бумаг; третья - на этапе государственной регистрации отчета об итогах выпуска [1].

\section{Порядок перехода прав на цифровые права}

Переход цифровых прав очень схож с переходом прав по бездокументарной ценной бумаге. Так, в соответствии с ч. 7 ст. 8 Закона об инвестиционных платформах, утилитарное цифровое право возникает у первого приобретателя, переходит от одного лица к другому лицу и (или) прекращается с момента внесения информации об этом в инвестиционной платформе в соответствии с правилами этой инвестиционной платформы (аналогичные положения содержатся в п. 2, 3 ст. 149.2 ГК РФ). Следовательно, правообладателем как цифровых прав, так и бездокументарных ценных бумаг является лицо, указанное в соответствующем качестве в информационной системе или реестре бездокументарных ценных бумаг. Как более упрощенно отмечают некоторые авторы: по общему правилу обладателем цифрового права считается лицо, которое может им распоряжаться [8].

В качестве промежуточного итога можно выразить сомнение в целесообразности выделения такого «нового» объекта права, как цифровые права, ввиду практически полного дублирования содержания и порядка реализации цифровых прав с бездокументарными ценными бумагами, с той лишь разницей, что распоряжение и осуществление цифровыми правами осуществляются в информационной си- 
стеме. Вместе с тем, помимо установленных законом требований к такой информационной системе, ее технологическая сущность ничем не отличается от тех электронных реестров, которые ведутся реестродержателями бездокументарных ценных бумаг.

\section{Цифровое свидетельство}

Однако на введении в оборот сомнительной целесообразности цифровых прав законодатель не остановился. Статья 9 Закона об инвестиционных платформах закрепила совершенно новую ценную бумагу - цифровое свидетельство, под которым понимается неэмиссионная бездокументарная ценная бумага, не имеющая номинальной стоимости, удостоверяющая принадлежность ее владельцу утилитарного цифрового права, распоряжаться которым имеет возможность депозитарий, и закрепляющая право ее владельца требовать от этого депозитария оказания услуг по осуществлению утилитарного цифрового права и (или) распоряжения им определенным образом. Следовательно, в обороте появилась не имеющая номинальной стоимости ценная бумага, содержанием которой является право требования оказания услуг по осуществлению имеющего экономическую стоимость права требования, являющегося содержанием утилитарного цифрового права. Такая конструкция, помимо несоответствия природе бездокументарной ценной бумаги в части отсутствия номинальной стоимости, что само по себе представляется абсурдным, вызывает недоумение своим нагромождением различных по своей природе прав в отношении одного имущественного права.

Интересным является положение, в соответствии с которым при выдаче цифрового свидетельства депозитарий в соответствии с условиями осуществления депозитарной деятельности присваивает ему уникальное условное обозначение, позволяющее идентифицировать его среди иных цифровых свидетельств без обращения к информачии о содержании утилитарного циифрового права, в отношении которого выдано это цифровое свидетельство. При этом законодатель допускает обременение и обращение взыскания на цифровое право путем обращения взыскания или обременения цифрового свидетельства. Как можно обратить взыскание на ценную бумагу, которая не только не имеет номинальной стоимости, но и содержание которой может быть неизвестно кредитору - остается загадкой. Более того, реализация перехода, а также обременение удостоверенного цифровым свидетельством утилитарного цифрового права, судя по всему, потребует двойного учета - оператором информационной системы и депозитарием.

С учетом того, что Закон об инвестиционных платформах направлен на урегулирование отношений, связанных с инвестированием, такое усложнение условий реализации подобных инвестиций вряд ли пойдет на пользу инвестиционным платформам.

\section{Вывод}

Таким образом, признавая нецелесообразность цифровых прав, следует безоговорочно согласиться с Сергеем Васильевичем Сарбашем в том, что «совершенно бесплодной и даже вредной для цифровизации экономики является необходимость каждый раз указывать на цифровую форму в законе» [7]. Цифровое право является лишь формой существования права требования, но никак не новым самостоятельным объектом гражданских прав.

\section{СПИСОК ЛИТЕРАТУРЫ}

1. Галкова, Е. В. Правовое регулирование эмиссии ценных бумаг по российскому праву и праву зарубежных стран (сравнительно-правовой аспект) / Е. В. Галкова. - М. : Статут, 2014. -240 с.

2. Лаптева, А. М. Правовой режим токенов / А. М. Лаптева // Гражданское право. - 2019. - № 2. C. 29-32.

3. Наумова, О. Мошенничество в сделках с недвижимостью по копиям документов / О. Наумова // Жилищное право. - 2019. - № 10. - С. 61-90.

4. Савельев, А. И. Некоторые риски токенизации и блокчейнизации гражданско-правовых отношений / А. И. Савельев // Закон. - 2018. - № 2. C. 36-51.

5. Сбежнев, В. А. Цифровые инвестиции в Российской Федерации / В. А. Сбежнев // Налоговый вестник - Консультации. Разъяснения. Мнения. -2019 . - № 12. - С. 10-25. 
6. Тарасенко, О. А. Особенности закупочной деятельности Банка России / О. А. Тарасенко // Банковское право. - 2019. - № 6. - С. 35-42.

7. Цифровые права как новый объект гражданского права / Л. Новоселова, А. Габов, А. Савельев, А. Генкин, С. Сарбаш [и др.] // Закон. - 2019. № 5. - С. 31-54.

8. Шестакова, Е. Цифровые права и электронные сделки. Какое будущее у цифровизации юридического сопровождения бизнеса / Е. Шестакова, А. Жиркова // Финансовая газета. - 2019. - № 28. C. $10-11$.

\section{REFERENCES}

1. Galkova E.V. Pravovoye regulirovaniye emissii tsennykh bumag po rossiyskomu pravu i pravu zarubezhnykh stran (sravnitelno-pravovoy aspekt) [Legal Regulation of the Issue of Securities in Russia (Comparative Legal Aspect)]. Moscow, Statut Publ., 2014. 240 p.

2. Lapteva A.M. Pravovoy rezhim tokenov [The Legal Regime of Tokens]. Grazhdanskoye pravo [Civil Law], 2019, no. 2, pp. 29-32.

3. Naumova O. Moshennichestvo v sdelkakh s nedvizhimostyu po kopiyam dokumentov [Fraud in Real Estate Transactions on Copies of Document].
Zhilishchnoye pravo [Housing Law], 2019, no. 10, pp. 61-90.

4. Savelyev A.I. Nekotoryye riski tokenizatsii i blokcheynizatsii grazhdansko-pravovykh otnosheniy [Some risks of tokenization and blockchainization of civil law relations]. Zakon [The Law], 2018, no. 2, pp. 36-51.

5. Sbezhnev V.A. Tsifrovyye investitsii v Rossiyskoy Federatsii [Digital Investments in the Russian Federation]. Nalogovyy vestnik - Konsultatsii. Razyasneniya. Mneniya [Tax Herald - Consultations. Explanations. Opinions], 2019, no. 12, pp. 10-25.

6. Tarasenko O.A. Osobennosti zakupochnoy deyatelnosti Banka Rossii [Features of the Procurement Activities of the Bank of Russia]. Bankovskoye pravo [Bank Law], 2019, no. 6, pp. 35-42.

7. Novoselova L., Gabov A., Savelyev A., Genkin A., Sarbash S. et al. Tsifrovyye prava kak novyy obyekt grazhdanskogo prava [Digital Rights As a New Object of Civil Law]. Zakon [The Law], 2019, no. 5, pp. 31-54.

8. Shestakova E., Zhirkova A. Tsifrovyye prava i elektronnyye sdelki. Kakoye budushcheye u tsifrovizatsii yuridicheskogo soprovozhdeniya biznesa [Digital Rights and Electronic Transactions. What is the Future of Digitalization of Legal Support of Business]. Finansovaya gazeta [Financial Newspaper], 2019, no. 28, pp. 10-11.

\section{Information About the Author}

Alexey Yu. Churilov, Candidate of Sciences (Jurisprudence), Analyst, Scientific and Educational Center "Intellectual Property and Intellectual Rights", Law Institute, Tomsk State University, Prosp. Lenina, 36, 634050 Tomsk, Russian Federation, Lefikantor@yandex.ru, https://orcid.org/0000-0001-9435-1626

\section{Информация об авторе}

Алексей Юрьевич Чурилов, кандидат юридических наук, аналитик Научно-образовательного центра «Интеллектуальная собственность и интеллектуальные права» Юридического института, Томский государственный университет, просп. Ленина, 36, 634050 г. Томск, Российская Федерация, Lefikantor@yandex.ru, https://orcid.org/0000-0001-9435-1626 